\title{
La Araucana revisada: La Asinaria de Rodrigo Fernández de Ribera como crítica de la propaganda aristocrática y de la actitud imperialista
}

\author{
La Araucana Revisited: Rodrigo Fernández de \\ Ribera's La Asinaria as Critique of Aristocratic \\ Propaganda and Imperialist Attitude
}

TEREsa HiergeIsT

Instituto de Romanística

Universidad de Erlangen-Núremberg

Bismarckstr. 1. Erlangen, 91054. Alemania

teresa.hiergeist@fau.de

Orcid ID 0000-0001-7816-5364
RECIBIDO: 19 DE FEBRERO DE 2018 ACEPTADO: 22 DE MARZO DE 2018
Resumen: La Asinaria de Rodrigo Fernández de Ribera es un texto hasta ahora poco comentado en el contexto de la investigación literaria, lo que sugiere que solo ha generado reducido interés estético y cultural. A través de una lectura en relación con su referencia intertextual a La Araucana de Alonso de Ercilla, que relaciona el discurso y las prácticas de la autorrepresentación de los nobles y de la colonización con la obra, el presente artículo explora el texto como sátira que expresa una actitud crítica frente a la aristocracia y a un imperialismo desconsiderado. Se argumenta la actitud humanista de la obra, que se opone a las élites sociales, a sus hábitos, a sus comportamientos y a sus formas de autoestilizarse mediante géneros propagandísticos como la epopeya.

Palabras clave: La Araucana. La Asinaria. Intertextualidad. Imperialismo. Sátira.
Abstract: Rodrigo Fernández de Ribera's La Asinaria has only sparsely been analyzed in the context of literary investigations, indicating a rather scant aesthetic and cultural interest. By looking at the text in relation with its intertextual reference to Alonso de Ercilla's La Araucana, which connects the discourse and practices of the aristocrat's autorepresentation and of Spanish colonization with the work, the following article explores the text as satire expressing a critical attitude towards aristocracy and inconsiderate colonization. It will be argued that it proves to follow a humanist perspective objecting social elites, their habits, their behaviour and their forms of autorepresentation via propagandistic genres like the epopeya.

Keywords: La Araucana. La Asinaria. Intertextuality. Imperialism. Satire. 


\section{LA MARGINALIDAD DE LA ASINARIA EN LA INVESTIGACIÓN LITERARIA}

E 1 hecho de que La Asinaria de Rodrigo Fernández de Ribera sea muy poco estudiada se debe en primer lugar a la restringida disponibilidad de la obra. Escrita en las primeras décadas del siglo XVII, no se publicó ni en vida, ni inmediatamente después del fallecimiento del autor. Se tardó más de 400 años hasta que Carlos Petit Caro editara el manuscrito de los primeros 13 cantos, que hoy en día es propiedad de la Biblioteca Nacional, mientras que el resto de la obra se perdió en las profundidades de los archivos españoles (Núñez Rivera 1992, 58). Aparte de menciones de la obra en la Biografía del poeta sevillano Rodrigo Fernández de Ribera (Hazañas y la Rúa 93-97), en la Bibliografía bispano-latina clásica (Menéndez Pelayo 118-20) y el estudio descriptivo "Rodrigo Fernández de Rivera y su obra La Asinaria" de Pedro Lemus y Rubio en 1952, La Asinaria solo se ha tratado superficialmente y en notas a pie de página. En esas ocasiones, se califica principalmente como una imitación apuleyana de Las Metamorfosis poco lograda (Glenn 598), como parodia burlesca de la épica a la manera lúdica (como la Gatomaquía de Lope de Vega o La Mosquea de José de Villaviciosa), ${ }^{1}$ o se considera como encomio paradójico, al estilo del “Coloquio del porfiado” de Pedro Mexía (Núñez Rivera 2010, 64-65); ${ }^{2}$ comentarios que se niegan a otorgar una importancia estética, cultural o política a la obra y que la hacen parecer poco interesante para una investigación literaria.

Sin embargo, si se examina La Asinaria más detenidamente, uno se da cuenta de que, aunque la novela latina, las zoomaquias y los progymnasmata retóricos constituyen influencias importantes, la obra no se basa exclusivamente en ellas. Aunque la obra muestra a un protagonista asnal que sufre los golpes y los maltratos de su amo y que juzga severamente a la sociedad humana, La Asinaria se aleja del modelo antiguo al renunciar al hilo narrativo central de la transformación por la hechicera y al integrar episodios nuevos. ${ }^{3}$ A pesar

1. Se observan similitudes en estos textos sobre todo en el primer terceto de la obra ("El callado valor y hechos canto / del alma bestia, el animal constante, / apto ya a más de un acto heroico y santo", $L A s$ 17), que alude al famoso "arma virumque cano" de la Eneída, y en la invocación de las musas (LAs 17). Estos elementos generan la expectativa de un contenido bélico, que de hecho no se satisface.

2. Con ese modelo concuerda sobre todo en el inicio de la obra, donde se cuentan las características positivas de los asnos ("asno sufridor que merecía más venas y más plumas de poetas que se vacía al mar y el aire cría", $L A s$ 19) y se mencionan asnos "míticos" "Aquel sobre quien vido a Dios triunfante el pueblo desleal, y cuyo aliento de abrigo le sirvió en Belén infante", $L A s$ 17).

3. El hecho de que La Asinaria sea más que una imitación de Las Metamorfosis lo señala también Lemus y Rubio (343). 
de que combina una forma épica con protagonistas animales, la acción (como en el caso de las zoomaquias) no se inspira en la Ilíada (Bonilla Cerezo/Luján Atienza 13); a pesar de colocar un asno y sus hazañas en el centro del texto, el argumento es demasiado complejo para poder considerarlo como mero juego literario o ejercicio de estilo. ${ }^{4}$ La biografía del asno y sus malas experiencias con sus respectivos amos da lugar a una interpretación que va más alla del mero juego con las convenciones genéricas. ${ }^{5}$

En lo sucesivo, se intentará valorar el significado que suscita la interacción entre narración satírica, epopeya y género burlesco característica de $L a$ Asinaria, analizando el texto en relación con una posible referencia intertextual a La Araucana (1569) de Alonso de Ercilla. El objetivo consiste en demostrar, a través de la reconstrucción de trasfondos históricos y literarios y de una lectura de la obra como crítica de la aristocracia y de la explotación de los indígenas en el "Nuevo Mundo", que La Asinaria se puede leer como manifestación de un humanismo escéptico en cuanto a los discursos culturales y políticos del Siglo de Oro.

\section{La INTERTEXTUALIDAD ENTRE LA ARAUCANA y LA ASINARIA}

Ante la divergencia espaciotemporal y social de las diégesis de ambas obras, la intertextualidad entre La Araucana y La Asinaria no llama la atención a primera vista. En La Asinaria, el lector tiene que lidiar con tierras de España en vez de con colonias en ultramar, con la vida cotidiana en vez de con éxitos bélicos, con agricultores y mercaderes en lugar de con héroes y con animales en vez de con hombres, de manera que la dimensión política parece ser reducida. Sin embargo, en cuanto a la representación, así como a los eventos narrados, se aprecian ciertos paralelismos entre los dos textos: En primer lugar, los títulos de ambas obras se parecen, puesto que comienzan con el mismo sonido y están formados a partir de una derivación que proporciona al grupo de los protagonistas un sufijo generalizador. En segundo lugar, en ambos casos se trata de un poema largo con carácter narrativo en endecasílabos, subdividido en cantos, aunque varían con respecto a la forma estrófica ( $L a A s i-$

4. Muchas veces, el encomio paradójico es considerado como ejercicio retórico para entrenar el manejo del lenguaje literario (Cherchi 369), sin considerar su potencial crítico.

5. El cambio reiterado de los dueños y la estructura episódica de La Asinaria, que ya se encuentran establecidos en el texto apuleyano, cobran actualidad con el surgimiento y el auge de la novela picaresca en el siglo XVI. 
naria ofrece tercetos en vez de octavas) y a la rima (La Asinaria sigue el esquema $\mathrm{ABA} B \mathrm{BAB} C D C \mathrm{DCD}$ en vez de $\mathrm{ABA} \mathrm{BAB} \mathrm{CC}){ }^{6}$ En tercer lugar, el estilo de los dos textos es comparable por utilizar mucha retorica en ambos casos, ${ }^{7}$ por mostrar numerosas alusiones a la mitología, a la epopeya antigua, a la Biblia y a otros textos que subrayan la erudición del autor, y por ser aun así realista, puesto que se describen minuciosamente escenas despiadadas de dolor y de muerte. ${ }^{8}$ En cuarto lugar, la acción de las dos obras se transmite por una instancia homodiegética, que alterna con pasajes largos en discurso directo de personajes literarios (de guerreros en el caso de La Araucana, p. ej. 246-67, 497-99 o 627-30, y del asno protagonista en el caso de La Asinaria, 42-201). En quinto lugar, se pueden encontrar similitudes en cuanto al contenido. A pesar de las diferencias fundamentales de la acción, se encuentran varios párrafos análogos: ambos textos incluyen un episodio sobre la elección de un nuevo líder (en La Araucana cuando los caciques de Arauco se reúnen para designar a un nuevo capitán, 107-19, y en La Asinaria cuando varios animales discuten sobre el óptimo gobernador de la fauna, 104-05); ambos contienen un pasaje fantástico en el que un mago vuela alrededor de la tierra con el protagonista (Fitón con el narrador en primera persona en La Araucana, 73655, y Tiempo con el asno en La Asinaria, 141-45), mostrándoles desde arriba los diferentes continentes; 9 ambos describen la matanza de figuras embarazadas de una manera que suscita la identificación (en La Araucana un grupo de indígenas victimiza a las mujeres, 226; en La Asinaria se rasga el vientre de la madre del asno con espuelas, 57-59). Todas esas analogías indican que La Asi-

6. El hecho de que La Asinaria contenga solo 13 cantos y no 15 como La Araucana en el primer libro o 37 en los tres libros, se debe probablemente a que solo un fragmento del texto esté actualmente en disposición.

7. Según Mario Méndez Bejarano, el estilo de La Asinaria parece oscilar entre conceptismo y culteranismo (207), pareciéndose en este sentido a la escritura de Alonso de Ercilla, que se describe muchas veces como retorizada y solemne y a la vez realista (Vega de Febles 77-80; Pierce 17).

8. En parte, las correspondencias entre las dos obras abarcan hasta el micronivel, cuando a veces se utilizan las mismas palabras en las rimas (por ejemplo, en La Araucana: "No quiero detenerme más en esto / pues que no es mi intención dar pesadumbre, / y asi pienso pasar por todo presto, / huyendo de importunes la costumbre" 100; y en La Asinaria: "Dió en amusgar, y sin mover el labio / daba a entender su injusta pesadumbre / que malo es consenter cualquier resabio / que mala es aún en bestias la costumbre" 22).

9. El episodio del panorama del mundo es, por supuesto, tópico de la épica. Ya aparece en Morgante (1478) de Luigi Pulci, en Carlo famoso (1566) de Luis Zapata o en El Bernardo (1624) de Bernardo de Balbuena como medio para presentar saberes cosmográficos y trasmitir mensajes moralizadores (Friedlein 24-26; 278-79). Sin embargo, el hecho de que el mundo se presente mediante un mago (y no, como en otros casos, mediante una profecía, un sueño o una visión), sugiere una conexión entre La Araucana y La Asinaria. 
naria, aunque no sigue los esquemas de La Araucana hasta el mínimo detalle, establece una relación intertextual con ella. A continuación, se plantea la pregunta por el motivo de esa referencia, la cual se contestará centrándose en dos enfoques que se complementan: la sátira de la aristocracia y la crítica de un imperialismo radical.

\section{LA ASINARIA COMO SÁTIRA ANTIARISTOCRÁTICA}

Tanto trasladar un tema considerado entonces como sublime (la guerra) a un entorno cotidiano (la agricultura) como la mezcla de un género mayor (la epopeya) con un género menor (la narración satírica) representa una estrategia frecuentemente empleada para ridiculizar y criticar (Arellano 35). En La Asinaria, el hábito y las pretensiones de poder de la aristocracia resultan ser el objetivo más evidente de dicha disposición, ambos temas se centran en las negociaciones de la estructura social española de entonces (Menéndez Pidal 323). En el Siglo de Oro, la identidad de los nobles se encuentra en un periodo de transición: por un lado, siguiendo la tradición de la Reconquista recientemente terminada, se definen como caballeros que defienden el reino y sus valores, volviéndose así indispensables para la política del país (Mínguez 22); por otro lado, ese papel ya no refleja la realidad, puesto que los esfuerzos centralizadores y reformadores que comienzan a ser impuestos por los Reyes Católicos suprimen muchos de los privilegios aristocráticos, así como la autonomía política (Ríos Urruti 75) y la pacificación relativa del país durante el siglo XVI (Defourneaux 223; Roche 372), obligando a los nobles a llevar una vida pasiva y en favor del rey en la corte (Quintanilla Raso 65). A esto hay que añadir que la aptitud de los aristócratas para oficios administrativos se cuestiona por los eruditos burgueses con buena formación. Como consecuencia, son estos eruditos burgueses los que sustituyen progresivamente a los aristócratas en la gestión del Estado (Biersack 56). Muchos de los nobles intentan compensar esa crisis ensalzándose a sí mismos en público como héroes de guerra (Anglo 9) en las fiestas de cacería y en las corridas de toros protagonizadas por ellos mismos, ${ }^{10}$ así como en crónicas o epopeyas sobre la conquista del "Nuevo mundo" (como La Araucana), en las que discursivamente se crean peligrosos adversarios para poder presentar luego la ha-

10. En el Siglo de Oro, esas prácticas son privilegios de la aristocracia y representan una de muchas ocasiones en las que expone públicamente su estamento (Alcalá-Zamora 204). 
zaña de haberlos vencido y para probar así la legitimidad del estatus social superior. $^{11}$

Ahora bien, al mostrar agricultores en vez de guerreros nobles, la vida cotidiana en lugar de batallas, La Asinaria se distancia del principio de una declaración propagandística de los valores nobles. Ya en la "Dedicatoria", el texto se dirige a un "hidalgo pobre" privado de su capital simbólico, puesto que no se puede pagar la deliciosa comida, carece de posesiones espléndidas y solo dispone de un asno para cabalgar. Este último elemento, la falta del caballo y su compensación por un burro, se convierte en el tema central de la obra. Para comprender el valor satírico de ese cambio del contenido, hay que tomar en consideración la carga simbólica que se relaciona con ambos animales en el Siglo de Oro. Los caballos forman entonces un elemento decisivo para la autorrepresentación noble (Grange 322). Cuando los aristócratas aparecen en desfiles, en torneos o en otras festividades públicas a lomos de un caballo, se sitúan no solo espacialmente sino también simbólicamente por encima del pueblo (Roche 214). Los caballos son animales exclusivos, tan caros que solo las personas más adineradas pueden permitirse poseerlos (Roche 106); saber controlarlos equivale a ser idóneo como gobernante; ${ }^{12}$ y puesto que se utilizan en las guerras y se consideran como decisivos para ganar las batallas (Meyer 108), sirven para subrayar la indispensabilidad del jinete para el reino (Rieger 40). Los elementos constituyentes de la identidad noble y la superioridad asumida en comparación con las otras capas sociales se expresan por lo tanto en las construcciones discursivas de los caballos. Por eso, se vuelve más comprensible que muchas veces aparezcan como vehículo de la idealización del sujeto noble en los géneros propagandísticos (Hernando Sánchez 112). También La Araucana menciona caballos glorificados con cierta frecuencia para subrayar la ideología del poder legítimo de los jinetes, por ejemplo, cuando el caballo se describe con atributos típicos para expresar nobleza como "derivado / de la española raza poderosa, / [...] animoso, / veloz en la carrera y alentado, / [...] / y la furia sujeta y corregida / por un débil bocado y blanda brida" (228) o "doce caballos poderosos, / nuevos y ricamente enjaezados, / domésticos, ligeros y furiosos, / debajo de la rienda concertados" (364).

Aunque el asno también representa un animal de monta usual, su valorización en la sociedad del Siglo de Oro es completamente diferente a la del ca-

11. El hecho de que las crónicas sean una ocasión de la autoestilización de los nobles por excelencia, lo subraya Vega (115).

12. La idea subyacente es que quien es capaz de forzar un animal tan soberbio como el caballo a la obediencia, también se presenta apto para asumir cargos políticos (Raber/Tucker 15). 
ballo. El animal es asequible para los pobres, es utilizado a menudo en contextos agrarios y es considerado como simple y vulgar. ${ }^{13}$ Esa imagen poco glamurosa se realza por las connotaciones negativas que se le atribuyen en las historias naturales y textos religiosos. ${ }^{14}$ Esas mismas connotaciones siguen estando vigentes en el Siglo de Oro, cuando por ejemplo Gerónimo Cortés lo describe en Tratado de los animales terrestres y volátiles como "animal de poco respeto", de "mal talle" y de "ruin disposición" (39), y Luis de Granada en Introducción al símbolo de la fe lo califica como "perezoso" (75). Pruebas de esa alterización discursiva son los cultos de asnos en el contexto del carnaval, en los que el rey de la comunidad festiva lleva orejas de asno o en los que un asno vestido se venera en la catedral (Bochet 17-18).

Por lo tanto, La Asinaria utiliza esa discrepancia entre los discursos sobre el caballo y el asno explícitamente para frustrar la autorrepresentación ideológica de las élites sociales. Cuando el asno es descrito con los atributos y valores típicos de un aristócrata, cuando es designado como "noble" y se subraya que "a su valor [se debe] un establo / cual lo que un tiempo tuvo Andalucía / de tersa plata: estatua y retablo" (19), cuando es alabado: "Uno era siempre ¡y qué galán! su traje; / siempre retozador, siempre lozando, / que solo era mohino de linaje" (27), o cuando afirma: "Nací, de garanón, noble y discreto, asno de bien [...] Era asno, mi padre, de Castilla, yegua andaluz mi madre, [...] hermoso talle y gallardía, que imitaba al viento que su abuelo ser decía" (54), el texto rompe con las expectativas y crea una tensión cómica que desacredita el carácter constructivo de la identidad aristocrática. Se aplica el mismo principio para ridiculizar al jinete, que muestra desde el inicio del texto que es incapaz de controlar al animal, sobre lo que el narrador comenta: "gastaba rienda, espuela y esperanza, / y él con torpe meneo, a mi requesta, / ¡no!, siempre dijo sin catar crianza. / Púseme en pie buscando en la floresta / socorro a mi aflicción" (24). El asno se niega tan consecuentemente a someterse al hombre que este termina perdiendo su credibilidad; una idea que se lleva al extremo cuando el propietario decide colocar al asno sobre sus hombros para llevarlo en vez de dejarse llevar (29). ${ }^{15}$ Esa inversión carnavalesca se bur-

13. Sebastián de Covarrubias describe al asno como "animal conocido, domestico y familiar al hombre, de mucho provecho y poco gasto" $(1611,95)$.

14. En la Antigüedad, el asno se relacionaba con Dionisio, es decir con la fertilidad, la lascividad y el falo (Ordine 13); también en la Edad Media era asociado con el vicio (sobre todo con la gula, con la pereza y con la ignorancia) y se diabolizaba.

15. El motivo del jinete que lleva su caballo es común en las sátiras del Siglo de Oro y se utiliza para desmontar la soberbia aristocrática. Aparece por ejemplo en "Yo vnico Cauallero" (Romances varios... 57). 
la, a través de su carácter hiperbólico, de los intentos superficiales de los nobles de embellecer su imagen social. En ese contexto no sorprende que el afán caricaturesco de La Asinaria también cubra las estrategias literarias utilizadas para idealizar al caballo, diciendo de una asna que es "digna de dar caballos para Apolo" (79), "digna del tiempo de otro Cid, que diera / a ti la ilustre tumba que a Babieca” (79) ${ }^{16}$ o "con los asnos de Tuilo y de Vigilio, / mano a mano, señora, te paseas, / con los de Homero, Píndaro y Pompilio" (80). La referencia a las figuras míticas de la Antigüedad y de la Edad Media, que suele glorificar la caballería en las epopeyas, en combinación con el asno se convierte en una parodia absurda que desvela las intenciones que motivan ese acto de heroizar, es decir, perpetuar el poder aristocrático. En general, La Asinaria critica implícitamente a los nobles a través de su elección del animal de asistencia, expresando la inautenticidad de la autoimagen aristocrática a través de la sustitución de un animal considerado como noble por un animal dado por rústico, ${ }^{17}$ una estrategia corriente en los contextos satíricos de entonces. ${ }^{18}$ Así, la referencia de La Asinaria a La Araucana resulta ser apropiada en el sentido de que junto con el comportamiento y el hábito de la aristocracia se deconstruye la epopeya como foco de su propaganda.

Es bastante obvio identificar una herencia humanista en esa crítica, no solo porque se pueden determinar elementos típicos del humanismo como, por ejemplo, la referencia a modelos antiguos (tanto Las Metamorfosis de Apuleyo como el objetivo horaciano de "juntar lo dulce con lo provechoso" se mencionan explícitamente en la "Dedicatoria", $L A s$ 11) o la actitud moralista ante la decadencia de las costumbres, la hipocresía y la arrogancia general $;{ }^{19}$ sino también porque el asno tiene en el texto dos funciones: la de representar el

16. La comparación con caballos de guerreros heroicos para ilustrar la falta de realismo del protagonista noble se emplea también en Don Quijote, cuando se dice: "[a Alonso Quijano] le pareció que ni el Bucéfalo de Alejandro ni Babieca el del Cid con él se igualaba" (Cervantes 31).

17. Ese tema de la crítica de la decadencia e hipocresía de la nobleza se encuentra también en otras obras de Rodrigo Fernández de Ribera, por ejemplo en Antojos de mejor vista (1625), donde describe la vanidad y la arrogancia de unos caballeros nobles en un espectáculo público, o en $M e-$ són del mundo (1631), que ilustra la propensión de los diferentes clientes de una posada al vicio.

18. En la mayoría de los casos, ese principio se realiza en la literatura del Siglo de Oro reemplazando el caballo noble no forzosamente por un asno, sino por un rocín, que después frecuentemente se compara con un asno. Ver, por ejemplo: Cervantes 31; Romances varios... 57; Quevedo 1969a, 360; 1969b, 43; 1969c, 448-49.

19. En un largo pasaje moralizador no solo se designa a los nobles como asnales, sino a todos los miembros de la sociedad, es decir poetas, médicos, jurisconsultos, abogados, teólogos, mercaderes, caballeros, villanos, ladrones y cortesanos ( $L A s$ 45-59). No carece de (auto)ironía que esa "asnificación general" sea comunicada por un asno. Esta inclusión de la voz humanista en la crítica tiene que entenderse como estrategia para aumentar la credibilidad de un sujeto que predica la importancia de cuestionarse a sí mismo. 
no-caballo y la de desempeñar el cargo de portavoz de la crítica expresada, ${ }^{20}$ que se convierte en símbolo humanista a finales del siglo XVI. Se alaba en La cábala del cavallo Pegaso (1584) de Giordano Bruno, en La nobilitá dell'asino (1599) de Adriano Banchieri o en los Ensayos de Michel de Montaigne (1580) como animal tolerante, pacífico y sencillo, ${ }^{21}$ que muestra una astucia creativa alejada de las características institucionalmente acreditadas (Bochet 23). El gesto crítico de La Asinaria obedece, pues, a una lógica de hábito, según la cual los humanistas burgueses, que en este tiempo van dando sus primeros pasos como actores sociales influyentes, se distancian de la aristocracia a través de la desvalorización de su ideología, representando su figura positivamente en escena. ${ }^{22}$

\section{LA ASINARIA COMO SÁTIRA DEL IMPERIALISMO}

En lo que se ha demostrado hasta ahora, la referencia a La Araucana queda poco especificada y profundizada, puesto que se habría podido recurrir a otras epopeyas del Siglo de Oro más adecuadas para criticar la ideología aristocrática (como Carlo famoso de Luis Zapata, La Carolea de Jerónimo Sempere o La conquista de Granada de Duarte Dias). ${ }^{23}$ Por lo tanto, es de suponer que existen otras razones que motivan esta intertextualidad y que tienen que ver directamente con las colonias. El hecho de que La Asinaria elija varias veces a la población indígena como dispensador de sus metáforas y comparaciones a pesar de estar localizado en España, refuerza esta impresión. ${ }^{24}$ El que el título de las

20. Es el asno el que describe a los miembros de la sociedad como asnos y el que denuncia el adulterio de la mujer de uno de sus dueños rebuznando (LAs 160-63).

21. Esa imagen positiva del asno como figura de identifiación del humanista circula también en España, sus reflejos se encuentran en el texto sobre los animales de Gerónimo Cortés, que lo describe como modesto, paciente y sufrido (40), en el emblema moral "Felix qui propiis aevum transegit in parvis" de Sebastián de Covarrubias, que se ilustra con la figura de una cabeza de asno $(1978,213)$ o en el elogio del asno en el texto burlesco ya mencionado "Coloquio del porfiado" de Pedro Mexía.

22. Fernández de Ribera nació demasiado tarde (1582) para vivir la época del esplendor del humanismo español, sin embargo, el hecho de que estudiara filosofía y teología (Hazañas y la Rúa 6), trabajara como secretario para el marqués de Algaba y que participara activamente en la vida cultural de Sevilla, por ejemplo en certámenes poéticos y en tertulias literarias (Warren Haney 7-14), sugiere que estuvo en profundo contacto con las ideas humanistas.

23. Se refiere a las actitudes heterogéneas de la crítica en cuanto al posicionamiento de La Arauca$n a$ frente al imperialismo español, puesto que mientras que unos afirman que la obra glorifica la corona, otros defienden que se deja de lado al adversario araucano (Marrero-Fente 97; López-Chávez 55).

24. Por ejemplo: "el sol quería poner el cuerno de oro al indio bruto" ( $L A s 21)$, "No cual indio caimán adula y llora [el asno] / con los ojos al hombre, y con la boca / sus blancos huesos sin piedad devora" (LAs 25). 
dos obras analizadas equipare al pueblo auracano con los asnos representados, sugiere que la acción de La Araucana está simbólicamente puesta en escena por La Asinaria a través de los animales, como es frecuente en la literatura del Siglo de Oro, ${ }^{25}$ y esta equivalencia podría suponer una declaración sobre la actuación de los españoles en América o mostrar una realidad que deje oculta o revele solo parcialmente la epopeya. El análisis parte de las escenas presentes en ambas obras (ver supra), para después proponer una interpretación más general.

La escena de la discusión en la reunión de los animales sobre la manera óptima de gobernar representa una mezcla literaria inspirada por la búsqueda de un nuevo capitán de los indígenas en La Araucana y por un pasaje del Llibre de les besties (c. 1287) de Ramón Llull, que narra cómo un león y un caballo pretenden el título de gobernante de la fauna, siendo el león el que finalmente consigue dicho título (Llull 15). La Asinaria retoma esa fábula (sustituyendo al caballo por un asno $)^{26}$ y acentúa la disputa entre los dos candidatos. Sin embargo, a diferencia de la obra del catalán, Ramón Llull, La Asinaria defiende que el asno sería más apto para el gobierno por su inteligencia y su modestia ("manso en la adversidad y muy sufrido, / de su trabajo liberal, callado, / y de cualquier servicio agradecido" 105) y que el león solo gana porque intimida sistemáticamente a los votantes con su comportamiento agresivo ("el rugido del león temieron" 104; "que no rey desde entonces, mas tirano / es de los animales" 105; "rey furioso e inhumano" 105). El león y el asno también se describen de esa manera dicotómica fuera de la escena analizada: el primero es explícitamente designado como "rey sangriento" (17), mientras que el segundo es presentado como "símbolo de la mal conocida paciencia" (7) y se afirma que "no lo inquietan cuidados de la guerra" (25). Si se supone que los asnos simbolizan a los araucanos, es posible que el león represente a las élites españolas. Una suposición que se vuelve más evidente, porque el león es, junto con el

25. Ejemplos de este procedimiento son La segunda parte de Lazarillo de Tormes, y de sus fortunas y adversidades (1555) de Diego Hurtado de Mendoza, que se interpretó como "sátira política cortesana" que critica a Carlos v (Navarro Durán xx) o la El búbo gallego con las demás aves de España baciendo Cortes (1572) de Pedro Fernández de Castro, que parece ser una sátira en favor de los derechos históricos de Galicia (González López 339).

26. Es posible que esa sustitución no se deba solo a los afanes críticos descritos en el capítulo anterior, sino a la intención de acentuar la diferencia entre los adversarios que se presentan. Después de todo, Gerónimo Cortés describe al asno como "contrario del león", atribuyéndole rasgos diametralmente opuestos (28-29). Además, la intención puede hacer cargar a los indígenas de una connotación positiva, puesto que el modelo literario del asno apuleyano representa una figura popular, relacionada con la diversión (ver Schlam 7). 
águila, el animal heráldico más popular del Siglo de Oro (Meier 42) y los guerreros nobles españoles a menudo se designan en las epopeyas o en los libros de caballería metafóricamente como leones para expresar su fuerza y su nobleza. ${ }^{27}$ En La Asinaria, esas características positivas son invertidas, ya que el león no aparece como gobernador ideal, sino como una figura brutal y violenta con sus súbditos, y su reinado no parece deberse a su idoneidad, sino a sus intereses de poder egoístas. En este sentido, el episodio de la discusión sobre el óptimo rey se podría leer como posicionamiento contra el procedimiento desconsiderado que se aprovecha de la tolerancia y de la debilidad de la población araucana, y como llamamiento a la moderación. ${ }^{28}$ Este mensaje se acentúa comparándolo con el pasaje de la elección del capitán de los araucanos, que transcurre sin dominancia ni disputa y en el que sale victorioso el más fuerte. ${ }^{29}$ Los araucanos parecen así más virtuosos y más honestos que los españoles. ${ }^{30}$

El hecho de que La Asinaria quiera concienciar sobre la actitud imperialista en las colonias, también se puede deducir de las escenas del vuelo por el mundo con la ayuda de un mago. En la descripción de los paisajes sobrevolados en La Asinaria, la parte sobre las colonias españolas está relativamente detallada. Se mencionan varias regiones de ultramar, como México, Perú, Chile y Brasil, al hacer referencia en parte a sus líderes indígenas ("de Moctezuma imperio", el "reino antiguo de los Incas luegos, / causando al aire envidia y vituperio" 144), mientras que en La Araucana se muestra una perspectiva colonialista española, hablando de la "Nueva España" (750), de "las primeras islas que descubrió Colón” (750), de Puerto Viejo "do la mina / de ricas esmeraldas fue hallada" (751) y de Lima, "la ciudad insigne de los Reyes, / silla de las Audiencias y virreyes" (752). La Asinaria menciona pues que hay una alternativa para sustituir la manera de gobernar el imperio español. ${ }^{31}$ Además, se apre-

27. Por ejemplo, en Amadís de Gaula se dice sobre el caballero Ardán Ganileo que tiene "semejanza de león” (Rodríguez de Montalvo cxxvi) o Antonio Luis Ribero presenta al Rey como "león soberano" (7).

28. En este sentido, La Asinaria acentúa la tendencia de La Araucana de justificar la colonización por un lado y de criticar el procedimiento inclemente, oportunista e injusto frente a los araucanos, por el otro (Mejías López 49).

29. El principio igualitario que forma la base del gobierno de los indígenas y así su carga utópica, lo subraya ya Pollmann (139).

30. La confrontación de los géneros literarios de la fábula y de la epopeya refuerza ese mensaje, porque opone igualmente la moral a las pretensiones de dominación.

31. El hecho de que el episodio del vuelo por el mundo sirva para subrayar la grandeza del imperio colonial español, también en comparación con las posesiones portuguesas, lo subraya también Nicolopulos (265-67). 
cia la valorización divergente de España en los dos textos: Mientras que en $\mathrm{La}$ Araucana el tono para hablar sobre la metrópoli es elogioso ("Mira a Valladolid, que en llama ardiente / se irá como la fénix renovando" 747; "Mira luego a Madrid, que buena suerte / le tiene el alto cielo aparejada" 748; "Mira a Sevilla, ves la realeza / de templos edificios y moradas, / el concurso de gente y la grandeza / del trato de las Indias apartadas" 749), en La Asinaria se esboza una imagen explícitamente negativa del país, sobre el que se proclama: "volvimos, pues a España / cosa fea, sin que hallase un hombre el tiempo, en cuanto / del Mundo anduvo, que contento sea" (144). La fricción que producen las dos versiones puede dar el impulso para una relativiziación de la autoimagen española y para una reflexión sobre la actuación de la corona en las colonias. ${ }^{32}$

La escena de la matanza de las figuras embarazadas es la que más difiere en las dos obras. Mientras que en La Araucana la muerte de las mujeres de los adversarios ocurre en el contexto de una batalla bélica, en La Asinaria la madre del protagonista muere durante el trabajo al ser maltratada y picada fuertemente con espuelas; mientras que en el primer caso los agresores son los indígenas, en el segundo lo son -si se sigue la lógica de que los asnos representan a los chilenos y sus dueños a los colonizadores- los españoles. A pesar de esa divergencia, las dos escenas tienen en común su gran intensidad emocional: $\mathrm{La}$ Araucana describe las atrocidades que cometen los araucanos para demostrar que estos no conocen la clemencia, utilizando una figuración muy concreta y grotesca al describir los fetos que salen de las barrigas de sus madres muertas: "no tienen miramiento a las preñadas, / mas los golpes al vientre encaminaba, / y aconteció salir por las heridas / las tiernas pernezuelas no nacidas" (226). La Asinaria, reduciendo considerablemente la brutalidad, adquiere su expresividad a través de la personalización de la escena:

Aquí volvió a sentir de nuevo espuelas

mi embarazada madre en sus ijares, y el corazón, que las temió, en sus telas.

¡Ah Amigo! ¡Cómo tienen los pesares

dominio sobre un asno sin ventura, antes que nazca a despoblar pajares! (57)

32. Según Roger Friedlein, el motivo tradicional de la cosmovisión en la epopeya se relaciona la mayoría de las veces con la revelación de la falsa seguridad y de la arrogancia de los lectores (279). En este sentido, también la convención literaria empuja hacia una lectura reflexiva. 
La formulación pleonástica "volvió a sentir de nuevo" iconiza la duplicación de la violencia ejercida, porque las espuelas no perforan solamente el vientre del asna, sino que hieren también al feto en el interior. La piel pierde su función protectora y ya no garantiza la división entre el mundo interior y exterior, lo que también repercute estilísticamente en la juxtaposición y combinación de esas isotopías ("embarazada"-“ijares", "corazón"-“telas"). ${ }^{33}$ Por otro lado, la asna se convierte en una figura de identificación a través de las personificaciones ("embarazada", "madre”), la interjección apostrófica “¡Ah Amigo!” y la tematización explícita de los sentimientos del asna (sentir, temer). Este componente personal y afectivo está reforzado por el largo lamento del protagonista que narra la muerte de su madre. ${ }^{34}$

Ahora bien, este pasaje se puede considerar como una escena clave de la obra, porque sus elementos determinantes vuelven a aparecer en otros cantos, de manera que permite conclusiones más generales. Mientras que en La Araucana los indígenas aparecen continuamente en un contexto bélico como valientes combatientes, al igual que sus adversarios españoles, no ocurre lo mismo en La Asinaria, donde los asnos aparecen siempre como figuras que satisfacen unas necesidades econónimas (como animales de tiro en la agricultura o animales de carga en el comercio), representando el papel de la víctima y siendo expuestos a golpes, a maltrato, a la falta de mantenimiento, de alojamiento y de una alimentación adecuada y a la sobreexplotación por parte de sus respectivos dueños $(35,57,79,121,152) .{ }^{35}$ Sus propietarios los ven como objetos de uso de los que pueden aprovecharse a su libre albedrío, sin tomar en consideración sus necesidades. El asno describe su situación como "estado

33. También la elección del modo de la narración subraya esa ambivalencia. Al oscilar entre focalización cero e interna, se difuminan los límites fijos, de manera que la violencia representada puede parecer una superación de límites ilegítima.

34. Un cambio decisivo entre las dos versiones reside en el hecho de que en La Araucana mueran madre y feto, mientras que en La Asinaria el bebé sobrevive, lo que le permite contar su historia. Ese cambio subraya la táctica de silenciamiento de los adversarios, a la que recurren muchas epopeyas (ver Davis 5), y es en este sentido más crítico.

35. La apreciación de los indígenas a través de su comparación con asnos a primera vista parece poco plausible, puesto que la animalización se utiliza ordinariamente como táctica para desvalorizar. Sin embargo, si se toma en consideración que los indígenas son frecuentemente representados como bestias salvajes en los textos sobre la colonización -por ejemplo, en La Arauca$n a$ se los trata de jabalíes $(178,619)$, toros $(157,179,545)$ o fieras $(130,805,921)-$, relacionarlos con un animal doméstico y útil en cierto modo supone una mejora de su imagen. $\mathrm{Al}$ retomar la forma de representación de las epopeyas y crónicas y al cargarla positivamente, La Asinaria posiblemente no solo lanza una revalorización de los indígenas, sino también una reflexión sobre la manera de hablar sobre ellos. A la misma estrategia recurre Bartolomé de las Casas cuando habla de los indígenas como "ovejas mansas" (77). 
pobre" (54), "siempre aumentando al sufrimiento daños" (54), y a sí mismo como "al bien siempre olvidado, / aunque al trabajo y a los males pronto" (106). Basándose en esta interpretación del símil de los indígenas con los asnos, que no acontece únicamente en las alusiones explícitas, sino a lo largo de toda la narración, se extrae la conclusión de que las guerras en Chile (o quizás también las guerras en las colonias en general) no son una confrontación bilateral, sino una explotación y una dominación de los indígenas por parte de los españoles. Igualmente, este componente de la obra se podría leer como crítica de La Araucana y de la ideología del género de la epopeya, en el sentido de que la representación de los indígenas como héroes combatientes, que se ha interpretado muchas veces como indicio de un reconocimiento del poder de actuación de los araucanos (Dichy-Malherme 87), se desenmascara como estrategia discursiva empleada por los españoles para disimular que la conquista es más bien una sumisión unidireccional y objetivadora.

En ese mismo sentido podría interpretarse el hecho de que La Araucana dé voz a los indígenas, haciéndoles testimoniar su beligerancia, sus anhelos de venganza y su agresividad -elemento que también se ha interpretado muchas veces como prueba de una actitud a favor de ellos (Raviola Molina 131; Serés $57,69)-$. Al quejarse de la injusticia de sus dueños y al clamar su inocencia, el asno de La Asinaria de cierto modo desacredita esa voz araucana como proyección eurocéntrica, que sirve para legitimizar la guerra como justa, ${ }^{36}$ poniendo el enfoque en que la verdadera voz de los araucanos, y con ella la realidad sobre la guerra, se silencia intencionadamente. ${ }^{37}$ Esto podría ilustrar otra escena, en la que el asno repetidamente intenta establecer contacto con el personaje humano de diferentes maneras, pero este se niega a la idea de que haya un animal con capacidades comunicativas (LAs 22-27). El propietario reacciona con una resistencia creciente a las pruebas cada vez más evidentes de que el asno es un sujeto, puesto que reconocerlo significaría poner en duda su manera de tratarlo. Incluso cuando el asno se dirige al campesino en castellano, el narrador, en primera persona, queda incrédulo, atónito y sin palabras:

36. En el Siglo de Oro, las guerras se solían considerar como justas, si a la larga servían para disipar una amenaza exterior y para restablecer la paz (García Hernán 36). Al mostrar que una de las motivaciones para la intervención militar en las colonias son los intereses económicos, $\mathrm{La}$ Asinaria la califica implícitamente como injusta.

37. También el hecho de que La Asinaria, localizándose en Europa, en cierto modo represente la retransmisión de la epopeya -que La Araucana trasladó a las colonias- a España, puede sensibilizar respecto al gesto de apropriación etnocentrista que acompaña la colonización. 
el rojo humor que hasta allí caliente

por mis pulsadas venas discurría, paró a la fuerza del horror presente.

Pegóseme la lengua también fría, robó el miedo el color, que el caluroso cansancio al rostro ya sacado había.

Quedé a vista, Señor, del portentoso caso, inmóvil cual piedra, el erizado pelo huyendo del cuero pavoroso. [...]

$[\mathrm{M}] \mathrm{e}$ vi, Señor, del asno saludado. (LAs 36)

La escena invierte los papeles entre el campesino y su asno. Predomina la isotopía de estatismo ("el rojo humor [...] paró", "pegóseme la lengua", "fría", "robó [...] el color", "inmóvil cual piedra", "me vi [...] saludado"), que objetiviza al campesino y lo priva de su superioridad habitual. El hecho de que el hombre pierda su capacidad de hablar en el momento en el que el asno la adquiere, ilustra por un lado el carácter interactivo de las relaciones de poder y así también su reversibilidad, y por otro lado hace alusión al reparto de voces desigual en la epopeya. En conclusión, se puede decir que La Asinaria hace referencia a La Araucana para crear un contrapeso a la agresividad, a la alterización de los indígenas y a la explotación de las colonias, así como al gesto heroizante de las epopeyas y para relativizar y poner en duda esta ideología imperialista. En ese contexto, el posicionamiento queda ambivalente, puesto que, por un lado, se acentúa la toma de partido de La Araucana a favor de un trato justo hacia los indígenas y, por el otro, esta misma es denunciada como portavoz de una ideologia imperialista e ideológica.

\section{ConCLusión}

El objetivo del artículo era explorar el potencial cultural y político de La Asinaria. Focalizando las relaciones intertextuales entre ella y La Araucana, así como el juego con las convenciones genéricas actualizadas por la obra, se ha demostrado que, al integrar un mensaje crítico, la obra va más allá de una mera imitación de un modelo clásico o un mero ejercicio de estilo. Por un lado, $L a$ Asinaria desvela la inautenticidad de la autorrepresentación aristocrática en una época de cambios sociales fundamentales. En este contexto, el género de 
la epopeya también se denuncia como vehículo que crea una apariencia que engaña a los lectores. Por otro lado, el texto puede interpretarse como una puesta en escena simbólica y satírica de la conquista de las colonias, que, retomando escenas de La Araucana y modificándolas, relativiza la ideología imperialista española, cuestiona un comportamiento demasiado agresivo y lúdicamente plantea la pregunta sobre alternativas posibles.

En ambos casos, La Asinaria se revela como un posicionamiento humanista en el que el escepticismo en cuanto a las élites aristocráticas así como una lucha contra la arrogancia y por la moral son perceptibles. Un análisis más profundo de la obra (que incluya los manuscritos no editados) promete ser muy fructífero, no solo porque puede indicar cómo los contemporáneos leyeron La Araucana, sino también porque muestra una actitud crítica en un imperio que parece ser tan intransigente como el español a finales del siglo XVI.

\section{OBRAS CITADAS}

Alcalá-Zamora, José. La vida cotidiana en la España de Velázquez: el retrato vivo y contradictorio de un imperio que inicia su decadencia. Madrid: Temas de hoy, 1994.

Anglo, Sydney. The Martial Arts of Renaissance Europe. New Haven: Yale UP, 2000.

Arellano, Ignacio. Poesía satírico burlesca de Quevedo: estudio y anotación filológica de los sonetos. Pamplona: Universidad de Navarra, 2003.

Biersack, Martin. Mediterraner Kulturtransfer am Beginn der Neuzeit: Die Rezeption der italienischen Renaissance in Kastilien zur Zeit der Katholischen Könige. München: Meidenbauer, 2010.

Bochet, Marc. L'Âne, le fob des animaux: De l'Âne biblique à l'âne littéraire. Paris: Champion, 2010.

Bonilla Cerezo, Rafael, y Ángel L. Luján Atienza. Zoomaquias: épica burlesca del siglo XVIII. Madrid: Iberoamericana, 2014.

Casas, Bartolomé de las. Brevísima relación de la destrucción de las Indias. 1552. Madrid: Cátedra, 1995.

Cervantes, Miguel de. Don Quijote de la Mancha. 1615. Madrid: Alfaguara, 2005. Cherchi, Paolo. "L'encomio paradossale nel manierismo". Forum Italicum 9 (1975): 368-84.

Cortés Valenciano, Gerónimo. Tratado de los animales terrestres y volátiles. Valencia: en casa de Juan Crisóstomo Garriz, 1615. 
Covarrubias Orozco, Sebastián de. Tesoro de la lengua castellana o española. Madrid: por Luis Sanchez, 1611.

Covarrubias Orozco, Sebastián de. Emblemas morales. 1610. Madrid: Fundación Universidad Española, 1978.

Davis, Elizabeth. Myth and Identity in the Epic of Imperial Spain. Columbia: Missouri UP, 2000.

Defourneaux, Marcelin. Spanien im Goldenen Zeitalter: Kultur und Gesellschaft einer Weltmacht. Stuttgart: Reclam, 1986.

Dichy-Malherme, Sarah. "El primer canto de La Araucana: una cartografía épica de Chile". Criticón 115 (2012): 85-104.

Ercilla, Alonso de. La Araucana. 1589. Madrid: Cátedra, 2005.

Fernández de Ribera, Rodrigo. La Asinaria. Sevilla: Bibliófilos sevillanos, 1947.

Friedlein, Roger. Kosmovisionen: Inszenierungen von Wissen und Dichtung im Epos der Renaissance in Frankreich, Portugal und Spanien. Stuttgart: Steiner, 2014.

García Hernán. La cultura de la guerra y el teatro del Siglo de Oro. Madrid: Silex, 2006.

Glenn, Richard. "Fernández de Ribera, Rodrigo". Dictionary of the Literature of the Iberian Peninsula. Vol. 1. Eds. Germán Bleiberg, Maureen Hrie y Janet Pérez. Westport: Greenwood Press, 1993. 598.

González López, Emilio. Los políticos gallegos en la corte de España y la convivencia europea: Galicia en los reinados de Felipe III y Felipe IV. Vigo: Galaxia, 1959.

Granada, Luis de. Introducción del símbolo de la fe. Madrid: Cátedra, 1989.

Grange, Yves. "La Mise en cour des chevaliers". Les Arts de l'équitation dans l'Europe de la Renaissance. Eds. Patrice Feanchet d'Espèrey y Monique Chatenet. Arles: Actes Sud, 2009. 318-37.

Hazañas y la Rúa, Joaquín. Biografía del poeta sevillano Rodrigo Fernández de Ribera y juicio de sus principales obras. Sevilla: Torres y Daza, 1889.

Hernando Sánchez, Carlos José. "El caballo y la corte: cultura e imagen ecuestre en la monarquía de España (1500-1820)". Mil años del caballo en el arte bispánico. Ed. Manuel Delgado. Madrid: Nuevo Milenio, 2002. 107-47.

Lemus y Rubio, Pedro. "Rodigo Fernández de Rivera y su obra La Asinaria". Boletín de la Real Academia Española 32 (1952): 337-59.

Llull, Ramon. Llibre de les bèsties. c. 1287. Barcelona: Ediciones 62, 1965.

López-Chávez, Celia. Epics of Empire and Frontier: Alonso de Ercilla and Gaspar de Villagrá as Spanish Colonial Chroniclers. Norman: Oklahoma UP, 2016. Marrero-Fente, Raúl. Poesía épica colonial del siglo XV: historia, teoría, práctica. Madrid: Iberoamericana, 2017. 
Meier, Frank. Mensch und Tier im Mittelalter. Ostfilder: Thorbecke, 2008.

Mejías López, William. Las ideas de la guerra justa en Ercilla y en La Araucana.

Santiago de Chile: Editorial Universitaria, 1992.

Méndez Bejarano, Mario. Diccionario de escritores, maestros y oradores naturales de Sevilla y su actual provincia. Sevilla: Padilla, 1989.

Menéndez Pelayo, Marcelino. Bibliografía bispano-latina clásica. Madrid: Tello, 1902.

Menéndez Pidal, Ramón. Historia general de las literaturas hispánicas. Vol. 2. Barcelona: Barna, 1951.

Meyer, Heinz. Der Mensch und das Pferd: Zur Geschichte und Gegenwart einer Mensch-Tier-Beziehung. Hamburg: Dr. Kovaæ, 2014.

Mínguez, José María. "Sociedad feudal, guerra feudal”. La guerra en la Edad Media. Ed. José Ignacio de la Iglesia Duarte. Logroño: Instituto de Estudios Riojanos, 2007. 17-48.

Navarro Durán, Rosa. "Introducción". Novela Picaresca. Vol. 5. Ed. Rosa Navarro Durán. Madrid: Fundación José Antonio de Castro, 2010. XV-CC.

Nicolopulos, James. The Poetics of Empire in the Indies: Prophecy and Imitation in La Araucana and Os Lusíadas. Pennysylvania: State UP, 2000.

Núñez Rivera, J. Valentín. "Rodrigo Fernández de Ribera epigramático y Baltasar del Alcázar. Problemas de atribución: descripción y estudio del manuscrito 17524 de la Biblioteca Nacional”. Criticón 55 (1992): 53-89.

Núñez Rivera, J. Valentín. "Preliminar". Cristóbal Mosquera de Figueroa. Paradojas. Salamanca: Ediciones Universidad Salamanca, 2010. 11-170.

Ordine, Nuccio. Le Mystère de l'âne: Essai sur Giordano Bruno. Paris: Les Belles Lettres, 1993.

Pierce, Frank. Alonso de Ercilla y Zúñiga. Amsterdam: Rodopi, 1984.

Pollmann, Leo. Das Epos in den romanischen Literaturen: Verlust und Wandlungen. Stuttgart: Kohlhammer, 1966.

Quevedo, Francisco de. "Refiere las partes de un caballo y de un caballero". 1648. Obra poética. Vol. 2. Ed. José Manuel Blecua. Madrid: Castalia, 1969a. 358-60.

Quevedo, Francisco de. "Toreador que cae siempre de su caballo y nunca saca la espada". 1648. Obra poética. Vol. 2. Ed. José Manuel Blecua. Madrid: Castalia, 1969b. 43.

Quevedo, Francisco de. "Envía una yegua a descansar al Prado". 1648. Obra poética. Vol. 2. Ed. José Manuel Blecua. Madrid: Castalia, 1969c. 44849. 
Quintanilla Raso, Concepción. "La nobleza". Orígenes de la monarquía bispánica: propaganda y legitimación. Ed. José Manuel Nieto Sorio. Madrid: Dykinson, 1999. 63-104.

Raber, Karen, y Treva J. Tucker. "Introduction”. The Culture of the Horse: Status, Discipline, and Identity in the Early Modern World. Eds. Karen Raber y Treva J. Tucker. New York: Palgrave Macmillan, 2005. 1-42.

Raviola Molina, Víctor. "Elementos indígenas en La Araucana de Ercilla". vv. AA. Don Alonso de Ercilla inventor de Chile. Santiago de Chile: Universidad Católica de Chile, 1970. 81-136.

Ribero, Antonio Luis. El espejo del caballero en ambas sillas. Madrid: s.e., 1671.

Rieger, Dietmar. "Amadis und andere: Zu den literarischen Leitfiguren «ritterlicher» Eliten des 16. Jahrhunderts". Die Inszenierung der heroischen Monarchie: Frühneuzeitliches Königtum zwischen ritterlichem Erbe und militärischer Herausforderung. Ed. Martin Wrede. München: Oldenburg, 2014. 40-56.

Ríos Urruti, Fernando de los. Religión y Estado en la España del siglo XVI. México: FCE, 1957.

Roche, Daniel. La Gloire et la puissance: Histoire de la culture équestre XVI'-XIXe siècle. Paris: Fayard, 2011.

Rodríguez de Montalvo, Garci. Los cuatro libros de Amadís de Gaula. Salamanca: Junta, 1575.

Romances varios de diversos autores: añadidos, y enmendados en esta ultima impression. Madrid: Pablo de Val, 1655.

Schlam, Carl C. The Metamorphoses of Apuleius: On Making an Ass of Oneself. Chapel Hill: North Carolina UP, 1992.

Serés, Guillermo. "Algunas tradiciones de La Araucana". Perspectivas transatlánticas: estudios coloniales hispanoamericanos. Ed. Raúl Marrero-Fente. Madrid: Verbum, 2004. 53-76.

Vega, María José. "La idea de la épica en la España del quinientos". La teoría de la épica en el siglo XVI (España, Francia, Italia y Portugal). Ed. María José Vega. Vigo: Academia del Hispanismo, 2010. 103-13.

Vega de Febles, María. Huellas de la épica clásica y renacentista italiana en La Araucana de Ercilla. Miami: Universal, 1991.

Warren Haney, Robert. The Prose Satires of Rodrigo Fernández de Ribera. Ann Arbor: University Microfilms International, 1982. 